\title{
Interdisciplinarity and multiagent interactions for innovations in horticulture - paradigms beyond the words
}

Authors: P.É. Lauri, S. Simon, M. Navarrete, L. Parrot, F. Normand, M. LesueurJannoyer, J.P. Deguine

Keywords: agroecology, innovation, integrated sciences, participatory research, socialecological-agrosystem, systemic approach

DOI:

10.17660/ActaHortic.2016.1137.37

Abstract:

The progression towards sustainable horticulture is usually associated with scientific and methodological breakthroughs. As a consequence, the innovation processes in the fields of biology and ecology and their agronomic implementation are increasingly recognized as main drivers to improve horticultural systems. At the same time, a horticultural system cannot be designed without good knowledge of the social and economic contexts in which it is embedded; it has to be considered as an integrated social-ecological-agrosystem. For example, the cross-knowledge derived from interdisciplinary research constitutes the backbone for building ecologically-based crop ideotypes and cropping systems, including genetics, agronomy and social-environmental levers and constraints. Designing new horticultural systems in such a systemic framework is also relevant to develop and better implement knowledge exchange among agents. This strong intertwining of the different research fields poses new challenges. There is a need for more participatory research and scaling-up to achieve adoption of innovations along the horticultural chain. Thus, the former linear and top-down scheme, i.e., from basic science to applied science and fieldwork, is now reconsidered and the design of innovative agricultural production systems is viewed as an integrated, interactive and participatory process where agents are dynamically interacting. The new challenge is to better combine the detailed knowledge typical of the dominant reductionist paradigm generally oriented towards the "one-size-fits-all" objective and the paradigm of complexity where the "custom-fit" approach predominates. Progressing towards these frameworks of knowledge and relationships among agents poses epistemological questions about interdisciplinarity and hybridization between scientific and non-scientific (advisor, grower) knowledge. 